\title{
Determining the Effect of Age on the Reproductive and Stress Physiology of Octopus Bimaculoides Using Dermal Hormones
}

Stephanie Chancellor ( $\nabla$ schanc2@uic.edu )

University of Illinois at Chicago https://orcid.org/0000-0003-2735-1225

Bret Grasse

Marine Biological Laboratory

Taylor Sakmar

Marine Biological Laboratory

David Scheel

Alaska Pacific University

Joel S. Brown

Moffitt Cancer Center

Rachel M. Santymire

Georgia State University

\section{Research Article}

Keywords: Progesterone, Estrogen, Testosterone, Cortisol, Octopus bimaculoides, senescence

Posted Date: July 8th, 2021

DOl: https://doi.org/10.21203/rs.3.rs-655419/v1

License: (1) This work is licensed under a Creative Commons Attribution 4.0 International License.

Read Full License 


\section{Abstract}

Our goal was to validate the use of dermal swabs to evaluate both reproductive and stress physiology in the California two-spot octopus, Octopus bimaculoides. Our objectives were to: 1. use a biological stressor to validate glucocorticoid analysis; 2 . compare the concentration of reproductive hormones (estrogen and progesterone in females; testosterone in males) of reproductive $(\mathrm{N}=4)$ and senescent $(\mathrm{N}=$ 8) individuals to determine the effect of age on hormonal patterns; and 3. determine the relationship between glucocorticoid and reproductive hormone production. For the stress test, individuals were first swabbed and then chased around the aquarium with a net for five minutes. Afterwards, individuals were swabbed for 2 hours at 15-minute intervals to compare to a pre-stress test swab. Reproductive individuals responded to the stressor with a 2-fold peak of cortisol at 15 and 90 minutes. Six of eight senescent individuals did not produce a 2 -fold increase in cortisol. Reproductive females had significantly higher sex hormone concentrations (progesterone, estrogen, and testosterone) compared to senescent females. Reproductive males also had significantly higher levels of testosterone compared to their senescent counterparts. After the stressor, only reproductive males produced a 2-fold increase in testosterone concentrations, while sex hormones in females showed no change. Dermal swabs provide an effective and non-invasive means for evaluating octopus hormones, which can provide indicators of both reproductive state and perceptions of acute stressors.

\section{Introduction}

Ocean biomass continues to change as climate change progresses (Carozza, Bianchi, \& Galbraith, 2019). As some populations of species have decreased over the last decade, cephalopod populations have continued to increase (Pang et al., 2018). Looking at stress and reproductive hormones may provide more insight as to why these highly adaptable animals are successful in the face of these changes in their ecosystems due to climate change. Here, we demonstrate further validation of a minimal invasive technique to measure reproductive and stress hormones from Octopus bimaculoides dermal mucous. Furthermore, we aimed to show changes in stress and reproductive hormone concentrations throughout the reproductive and senescent life stages of this cephalopod.

Cephalopods live in a variety of habitats in the ocean, from the depths of the ocean to its shallow shores (Zylinski \& Johnsen, 2014). They also possess the uncanny ability to change the texture and color of their skin (Chubb et al., 2018; Hough, Case, \& Boal, 2016; Mather \& Alupay, 2016) and problem solve (Kuba, Byrne, Meisel, \& Mather, 2006; Richter, Hochner, \& Kuba, 2016). Although they tend to be regarded as intelligent animals, cephalopods have rather short life spans, on average living approximately 1.5- 2 years (Anderson, Wood, \& Byrne, 2002). Almost all octopuses are semelparous (Anderson, Wood, Byrne, \& Octopus, 2002; Hanlon \& Messenger, 2018), reproducing once in their life before a swift decline in health that ends in death.

In general, cephalopods invest in growth during the development phase of their life (Hanlon \& Messenger, 2018; Huffard, 2013). Growth and sexually maturity are regulated by secretions into the blood from the 
optic glands (Wells \& Wells 1959). Once sexual maturity is reached, the optic gland switches from overall growth of the animal to the growth of the ovary and its ducts in females (O'Dor \& Wells, 1978). Similarly, in males the optic gland controls the condition of the testes. Additionally, reproductive hormones including testosterone, estradiol- $17 \beta$, and progesterone, have been shown to regulate reproduction in cephalopods, gastropods, and bivalve mollusks (Lafont \& Mathieu 2007D’Aniello et al., 1996; Di Cosmo, Di Cristo, \& Paolucci, 2001), and are present in the sex organs and blood of octopuses (D'Aniello et al., 1996). Specially, for female reproduction, when preparing for egg laying, females devote all resources to their ovary, restricting all other growth (O'Dor \& Wells, 1978). These morphological changes of the reproductive system are paralleled with fluctuations in 17- $\beta$ estradiol and progesterone (Di Cosmo, Di Cristo, \& Paolucci, 2001). Estradiol and progesterone increase during vitellogenesis, or yolk development, and decreased as vitellogenesis is completed (Di Cosmo, Di Cristo, \& Paolucci, 2001). In males, testosterone stimulates spermiogenesis and reproductive behaviors (Avila-Poveda et al., 2015; D'Aniello et al., 1996).

Both male and female octopuses go through senescence. In semelparous species of octopus, after egg laying in females, their health declines and they begin to senesce which may be controlled by activation of the optic gland (O'Dor \& Wells, 1978). Males, whether they mate or not, see a similar decline in health around the same age as females lay their eggs (O'Dor \& Wells, 1978). Senescence can happen quickly (Mather, 2006; Gestal, Pascual, Guerra, Fiorito, \& Vieites, 2019) and in octopuses typically presents itself as a decline in feeding, retraction of skin around the eyes, uncoordinated movement, lesions on the body, and increased and undirected activity (Anderson et al., 2002). During this life stage, females typically are brooding eggs, while males show signs of senescence by being more mobile in search of a mate while they cease eating (Anderson et al., 2002; Mather, 2006).

Like reproductive hormones, glucocorticoid production vary throughout an animal's life span due to life events and metabolic differences between the life stages (Azevedo et al., 2019; Monfort, Mashburn, Brewer, \& Creel, 1988; Romero, 2004; Schell, Young, Lonsdorf, \& Santymire, 2013; Touma \& Palme, 2005). The Hypothalamic-pituitary-adrenal (HPA) axis activation is well known in vertebrates. Briefly, a perceived stressor results in the hypothalamus releasing corticotropin releasing hormone, which then stimulates the pituitary to release adrenocorticotrophic hormone (ACTH) (Moberg, 2000; Palme, Rettenbacher, Touma, ElBahr, \& Möstl, 2005). Once ACTH is released it stimulates the adrenal glands to release glucocorticoids, including cortisol and corticosterone. These steroids cause an increase in the release and production of glucose, which is used by the body to alleviate the stressor.

Although the stress pathways for cephalopods are unknown (Ottaviani, Caselgrandi, Petraglia, \& Franceschi, 1992), octopus stress hormones apparently respond to stressors, or changes in homeostasis, similarly to vertebrates (Larson \& Anderson, 2010; Chancellor, et al., Under Review). Juvenile cephalopods produce a higher concentration of glucocorticoids compared to older individuals (Chancellor, et al., Under Review). Both glucocorticoids can be measured in cephalopods; however, cortisol was determined to be the predominate stress hormone found in dermal secretions (Chancellor et al., Under Review). 
Understanding octopus stress physiology would provide a more robust understanding of cephalopod's life history along with providing insight to better diagnosis of health issues.

The challenge with studying cephalopod endocrinology is the sampling method, which often uses invasive techniques. For example, animals were euthanized so that the reproductive organs could be harvested at different life stages and analyzed for hormone concentration within the tissue (D'Aniello et al., 1996; Di Cosmo et al., 2001). Other studies used blood draws to measure hormones (Malham, Lacoste, Gélébart, Cueff, \& Poulet, 2002). Non-invasive techniques for measuring hormones while being able to repeatedly sample the same individual non-destructively are essential to protecting the welfare of octopuses. While sex and stress hormones have been measured non-invasively by feces (Avila-Poveda, Montes-Pérez, Benitez-Villalobos, \& Rosas, 2013; Larson \& Anderson, 2010), due to water circulation and group cultures in aquaria it can be difficult to collect feces in a standardized manner without constant monitoring. Mucus swabs of the octopus' skin surface may provide a non-invasive alternative for measuring hormones. Skin swabs have been used previously in freshwater fish (De Mercado, Larrán, Pinedo, \& Tomás-Almenar, 2018; Schultz et al., 2005), amphibians (Santymire, Manjerovic, \& SacerdoteVelat, 2018), and recently validated for use with various cephalopods (Chancellor et al., Under Review). The swabs allow for collection of samples from target individuals. Sampling can be repeated as needed. Ideally, swabbing exerts less stress than other techniques, and can be integrated into specific experiments.

Our goal is to expand the knowledge of cephalopod endocrinology by using dermal mucous swabs to measure glucocorticoid and reproductive hormones in reproductive and senescent life stages in the Two Spot Octopus (Octopus bimaculoides). O. bimaculoides was the first cephalopod to have their genome sequenced (Albertin et al., 2015) and further used extensively in studies (Albertin \& Simakov, 2020). The lifespan of 0 . bimaculoides is 15-17 months. Their three life history stages include juveniles (Boyle 1983), reproductive adults, and post-reproductive senescent adults (Robin et al., 2014). Death typically occurs within approximately 2 months after egg spawning (Forsythe \& Hanlon, 1988). Males senesce around the same time as the females (Anderson, Wood, Byrne, \& Octopus, 2002). Upon reaching adulthood, even in the absence of opportunities to mate, $O$. bimaculoides will senesce in 12-14 months.

Our objectives are to: 1) validate the use of dermal swabs to evaluate glucocorticoids and reproductive hormones; 2) determine the influence of life stage on hormone production; 3 ) examine the relationship among glucocorticoids and reproductive hormones; and 4) determine whether these hormones change significantly in response to an acute stress. We predict that senescent individuals will produce lower stress and reproductive hormones than reproductive individuals. We expect a larger and more immediate increase in stress hormones than reproductive hormones in response to an acute stressor. We also expect the increase in stress hormones will be higher in reproductive adults than in senescent adults.

\section{Methods}

\section{Ethical Statement, study site, and subjects:}


Due to cephalopods not being regulated by animal protocol in the United States, we did not need to apply for IACUC approval. However, we followed methods established by the regulations of the Directive 2010/63/EU for cephalopods (Fiorito et al., 2015a; Smith et al., 2013; Sykes, Baptista, Gonçalves, \& Andrade, 2012). Research was approved by Lincoln Park Zoo's Research Committee (approval \#2018016).

Study animals were individually housed in the mariculture room of the Marine Biological Laboratory in Woods Hole, Massachusetts, USA. Octopus bimaculoides was chosen due to availability and their increasing use in research since the publication of their genome (Albertin et al., 2015). Animals were wild caught from the California coast. Individuals were either reproductive adults ( 2 males and 2 females) or senescent adults ( 3 males and 5 females). Octopus enclosure included matieral to den, otherwise enclosure were bare.

\section{Swabbing method:}

Octopuses remained submerged in their aquarium during swabbing to minimize the additional stress due to the procedure. A researcher wearing powder-free latex gloves dipped a sterilized cotton swab with a plastic handle into the aquarium and rubbed the swab back and forth 4 times over approximately $2.5 \mathrm{~cm}$ of the mantle of each organism. We then placed swabs in a $2.0 \mathrm{ml}$ tube containing $1 \mathrm{ml}$ of $70 \%$ ethanol: distilled water. To ensure that the tube sealed properly, swab handles were cut to fit into the $2.0 \mathrm{ml}$ tube and parafilm wrapped around the lid to prevent leakage or evaporation. Researchers stored swabs in a $-32^{\circ} \mathrm{C}$ freezer.

\section{Validation of Glucocorticoid Analysis}

Before the stress test began, a baseline swab was taken for comparative purposes. To create a stress response, we disturbed each animal with a small net ensuring movement thoughout the aquarium for 5 minutes. Following the stress test, we swabbed the individual's skin surface underwater while they were in their dens. Swabs were taken every 15 minutes for the next 2 hours, producing 10 data points per individual. All individuals were individually housed. All hormones analyzed were from the results of the stress test.

\section{Sample processing and hormonal analysis}

We processed all samples at the Davee Center for Epidemiology and Endocrinology (Lincoln Park Zoo, Chicago, Illinois, USA). For 5 minutes, researchers shook sample vials holding plastic swabs on a mixer (Glas-col, Terre Haute, IN, USA; setting 60-70 rpm). Researchers removed swabs, and 500 $\mathrm{LL}$ of each sample was pipetted into new, pre-labelled $15 \times 75 \mathrm{~mm}$ test tube. Under forced air in a warm water bath at $60^{\circ} \mathrm{C}$, aliquots were dried down and $2-3$ glass beads were added to each tube, along with $500 \mu \mathrm{L}$ of phosphate buffered saline (PBS; $0.2 \mathrm{M} \mathrm{NaH}_{2} \mathrm{PO}_{4}, 0.2 \mathrm{M} \mathrm{Na}_{2} \mathrm{HPO}_{4}, \mathrm{NaCl}$ ). Researchers briefly vortexed tubes and then sonicated for 20 minutes. For 30 minutes, samples were shaken again on the Glas-col mixer $(60-70 \mathrm{rpm})$ and stored at $5^{\circ} \mathrm{C}$. Samples were analyzed on an enzyme immunoassay (EIA). 
By modifying a previously described cortisol EIA, we measured skin mucous swab cortisol concentrations (Loeding, Thomas, Bernier, \& Santymire, 2011). A polyclonal cortisol antiserum (R4866) and horseradish peroxidase (HRP), ligands provided by C. Munro (University of California, Davis, California) were used. This was then diluted to $1: 375,000$ and 1:200,000, respectively on a 96-well plate that was coated with goat anti-rabbit antibody (1:1000, Arbor Assay, Ann Arbor, MI). The cross-reactivity for cortisol in this assay has been previously reported (Loeding et al. 2011, Young et al., 2004). The cortisol EIA was biochemically validated in the laboratory by demonstrating parallelism between binding inhibition curves of swab hormones ( $2 x$ concentrated to 1:16) and the cortisol standard $(r=0.993)$ and significant recovery of cortisol added to pooled swab samples $\left(y=1.100 x-6.422, R^{2}=0.993, P<0.001\right)$. Assay sensitivity was $1.95 \mathrm{pg} /$ well and intra- and inter-assay coefficients of variation were $<15 \%$.

Progesterone polyclonal antiserum (CL425; University of California, Davis, CA) and HRP were used at a dilution of $1: 10,000$ and $1: 40,000$, respectively. Cross-reactivities of the progesterone antibody were as follows: progesterone, 100\%; 4-pregnen-3a-ol-20-one, 188\%; 4-pregnen-3ß-ol-20-one, 172\%; 4-pregnen-11 a -ol-3,20-dione, 147\%; 5 , -pregnan-3ß-ol-20-one, 94\%; 5 a -pregnan-3- a ol-20-one, 64\%; 5 a -pregnan 3,20-

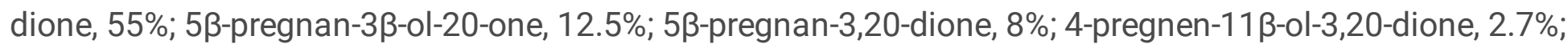

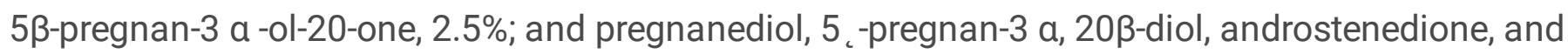
corticosterone, < 0.1\% (Graham, Schwarzenberger, Möstl, Galama, \& Savage, 2001; Loeding et al., 2011). Researchers validated the progesterone EIA by demonstrating: the parallelism between binding inhibition curves of swabs and the progesterone standard $(r=0.995)$; the significant recovery of exogenous progesterone $(0.78-200 \mathrm{pg} /$ well $)$ added to swabs $\left(y=0.910 \mathrm{x}-0.511, \mathrm{R}^{2}=0.999 ; \mathrm{P}<0.001\right)$.

Estradiol polyclonal antiserum (R0008; University of California, Davis, CA) and HRP were used at a dilution of 1:250,000 and 1:200,000, respectively. Cross-reactivities of the estradiol antibody were as follows: $100 \%$ with 17 -estradiol, $0.73 \%$ with estrone, and $<0.10 \%$ with estrone-3-sulfate, progesterone, testosterone, cortisol, corticosterone and androstenedione (Amaral, Rosas, Da Silva, Nichi, \& Oliveira, 2013). We validated the estradiol EIA by demonstrating the parallelism between binding inhibition curves of swabs and the estradiol standard $(r=0.994)$; and the significant recovery of exogenous estradiol $(1.95-250 \mathrm{pg} /$ well $)$ added to swabs $\left(y=0.999 x-3.461, R^{2}=0.998 ; P<0.001\right)$.

Testosterone horseradish peroxidase (HRP) ligands and polyclonal antiserum (R156/7; University of California, Davis, CA) were used at dilutions of 1:30,000 and 1:10,000, respectively. Antiserum crossreactivities for testosterone were as follows: testosterone, 100\%; 5a-dihydro- testosterone, $57.37 \%$; androstenedione, $0.27 \%$; androsteron and DHEA, $0.4 \%$; and cholesterol, $0.03 \%$. Cross-reactivity was $0.02 \%$ for the following: $\beta$-estradiol, progesterone, pregnenolone, hydrocortisone, cholic acid, chenodeoxycholic acid, cholic acid methyl ester, dehydrocholic acid, deoxycholic acid, lithocholic acid, glycholic acid, taurodeoxycholic acid, taurocholic acid, taurochendeoxycholic acid, and glycochenodeoxycholic acid (Dloniak et al., 2004; Loeding et al., 2011). We validated the testosterone EIA by demonstrating the parallelism between binding inhibition curves of swabs and the testosterone standard $(r=0.975)$; and the significant recovery of exogenous testosterone $(1.17-300 \mathrm{pg} /$ well $)$ added to swabs $(y=1.035 x-3.784$, $\left.R^{2}=0.999 ; P<0.001\right)$. 


\section{Data analysis:}

To validate the use of dermal swabs for glucocorticoid analysis, we considered that post-stressor hormone concentrations was elevated if it was at least twice (2-fold higher) than that of the pre-stressor sample (Romero, 2004). To determine the effect of age and stress hormones, concentrations of progesterone and estradiol for females and testosterone for males, we used analysis of variance (ANOVA) (SYSTAT13). Finally, cortisol was compared using 2-way ANOVAs with age classes and sexes as the independent variables.

\section{Results}

\section{Validation of dermal swabs for GC analysis}

For all individuals, there was not a 2 -fold change in dermal corticosterone for 2 hours after the stressor. We did not expect to see this 2 -fold change response from the senescent individuals. However, we did expect this change in the reproductive individuals. Furthermore, a 2-fold change in dermal cortisol was seen in 3 of the 4 reproductive individuals after a stressor. Due to this result, we are considering cortisol as the predominant glucocorticoid for Octopus bimaculoidies and will only be presenting cortisol results here.

\section{Effect of age on reproductive hormones}

Reproductive male and females had similar $\left(F_{1,38}=0.042 p<0.8\right)$ dermal cortisol. The senescent females had higher $\left(F_{1,78}=30.947, p<0.001\right)$ dermal cortisol than senescent males. Senescent males and females had higher $\left(F_{1,118}=46.169, p<0.001\right.$, Figs. 1 and 2$)$ dermal cortisol levels compared to reproductive males and females.

Both dermal progesterone $\left(F_{1,68}=130.236, p<0.001\right.$; Fig. 3$)$ and estradiol $\left(F_{1,68}=10.751, p<0.005 ;\right.$ Fig. 4) were higher in reproductive females than senescent females. Reproductive males had similar $\left(F_{1,48}=1.3\right.$, $p<0.25$ ) levels of dermal testosterone as senescent males (Fig. 5). Senescent males had higher $\left(F_{1,78}=\right.$ 25.72, $p<0.001)$ dermal testosterone levels than senescent females. For reproductive individuals, males had similar $\left(F_{1,38}=0.001, p<0.9\right)$ dermal testosterone levels as reproductive females (Fig. 5). Reproductive females had higher $\left(F_{1,68}=112.6, p<0.001\right)$ dermal testosterone than senescent females, but had similar $\left(F_{1,48}=1.5, p=0.225\right)$ levels as senescent males.

\section{Change in hormones after a stressor}

All reproductive females responded with at least a 2 -fold increase in dermal cortisol except for 1 female (OB4, Fig. 1B). None of the senescent females produced a 2-fold increase in dermal cortisol after the stressor, except for 1 female at 60 minutes (Fig. 1A). Reproductive males both responded to the stressor with a 2-fold increase in dermal cortisol (Fig. 2B). Senescent males did not produce a 2-fold response in dermal cortisol except for 1 male at time point 0 (Fig. 2A). 
For reproductive and senescent females, dermal progesterone, estradiol, and testosterone remained consistent over the 2-hours post-stressor period (Fig. 6). In senescent males, dermal testosterone remained consistent after the 2-hour period post-stress. Both reproductive males had a 2-fold peak at 105 minutes post-stressor (Fig. 7).

\section{Discussion}

Understanding cephalopod endocrinology is important for improving husbandry, in captivity, and learning how the rapidly change in their natural habitat impacts their populations. However, current techniques made it difficult to do so non-invasively in an aquatic genus like mollusks. Therefore, it was our goal to validate the use of dermal swab technique to collect and analysis glucocorticoid and reproductive hormones in a common ex situ managed octopus species, 0 . bimaculoides. Here, we successfully measured stress and reproductive hormones in 0 . bimaculoides using the non-invasive dermal swab technique, previously measured in amphibians (Santymire, Manjerovic, \& Sacerdote-Velat, 2018) and fish (Guardiola, Cuesta, \& Esteban, 2016; Simontacchi et al., 2008).

This is the first-time reproductive hormones have been measured using this technique, and the first with a cephalopod species. We also validated dermal glucocorticoid analysis using a biological stressor assay for this species. Chasing them for 5 minutes invoked elevated cortisol (a 2-fold increase in cortisol from pre-stressor samples) in all reproductive males (at 15 and 75 minutes) and reproductive females (at 0, 15, and 90 minutes) post-stressor except female OB4, who did not respond. Differences among individuals (Moberg \& Mench, 2000) can dertermine how quickly changes in stress hormones manifest on the skin's surface or variability in the swab's uptake of mucus may explain the time delays in observing a 2-fold increase. Additionally, for the senescent individuals, 2 males and 4 females showed no hormone response to the acute stressor. While we expect a stress hormone response to disturbing the octopus that is reproductive, there would be no adaptive reason for such a response in the senescent individuals. However, two senescent individuals had a 2-fold increase in response to the stressor (one Male, OB2 at 0 minutes, and one female, OB10, at 60 minutes).

Besides differences within species, there can also be differences between congeneric genus. Species differences in ecology or physiology can alter how they respond to stress (Mason, 2010). For example, after physiologically stimulating the stress pathway with ACTH in Octopus chierchiae, both male and female produce cortisol peaks at 15 and 45 minutes after an initiation of the stress pathways, respectively (Chancellor et. al., under review). In the present study, we used a biological stress test compared to the previous study where the physiologically stress pathway was initiated by injecting ACTH. Both measure a response to a physiological cascade resulting in elevated stress hormones; however, the stress pathway is initiated differently because it may depend on the individual and his/her experience and sensitivity to handling (Touma \& Palme, 2005).

Age also influences stress hormone production since glucocorticoids and can have different roles (Devenport et al. 1989) and functionality during different life stages (Palme, 2005). Between the age 
classes and sexes, senescent females had nearly three times $(\sim 1000 \mathrm{pg} / \mathrm{ml}$ swab) the amount of cortisol compares to reproductive females ( $300 \mathrm{pg} / \mathrm{ml}$ swab), reproductive males $(\sim 300 \mathrm{pg} / \mathrm{ml} \mathrm{swab})$ had nearly two times ( $500 \mathrm{pg} / \mathrm{ml}$ swab) of senescent males. This could be because senescent females were removed from their eggs hours before the experiment in order to perform the stress test. However, senescent males also had relatively higher levels of dermal cortisol compared to reproductive individuals. This could indicate that they are currently under chronic stress from senescence or have higher levels of cortisol concentrations during this life stage generally. This may provide evidence that senescence is chronically stressful or that cortisol pathways may be altered during this life stage, evidenced by lack of changes in dermal cortisol concentration. Chronic stress has been shown to dampen the response to acute stressors (Rich \& Romero, 2005). More investigation into stress pathways and senescence will be necessary to understand this relationship more fully. Senescent individuals may have higher dermal stress hormone concentrations because reproduction has been completed. Therefore, the resources once used for reproduction may be put towards a reallocation of resources and nutrients that are part of the senescence process, such as keeping the animal alive while they cease consuming food. This would suggest changes in physiology as an octopus becomes senescent.

Just as the role of stress hormones change throughout life stages, so should reproductive hormones. Mollusks possess the same reproductive steroid hormones as vertebrates, including estradiol 17- $\beta$, progesterone, and testosterone (Lafont \& Mathieu, 2007). In male octopuses, these hormones seem to be in higher concentrations in the sexual organs suggesting that cephalopods possess a comparable reproductive system under endocrine control (D'Aniello et al., 1996). Furthermore, in the female octopus, the reproductive system is the source of reproductive hormone production and morphological changes necessary for egg production (Di Cosmo, Di Cristo, \& Paolucci, 2001). Here, we found that in $O$. bimaculoides, estrogen and progesterone were higher for the reproductive females when compared to the senescent. This was expected since the senescent individuals had already mated, and all females had laid eggs. Furthermore, since all individuals were caught in the wild, we were unable to know when the reproductive females were going to lay eggs. In comparison, other egg laying vertebrates produce higher levels of progesterone before egg laying. As shown in other animals, such as mammals, after the egg is ovulated, reproductive hormones begin to decrease (Amaral, Rosas, Da Silva, Nichi, \& Oliveira, 2013). Estrogen and progesterone levels increase during egg development and preparation of egg laying and then decrease after the reproductive system was primed to lay eggs (di Cosmo et al 2001). These hormones may be less active in regulating egg-tending behaviors.

Testosterone concentrations also changed with life stage. Dermal testosterone concentrations for senescent males and females were lower than reproductive individuals. Reproductive males and females had similar levels of testosterone. Similarly, testosterone is known to decrease as human males get older (Kaufman, T'sjoen, \& Vermeulen, 2012; Vermeulen, Rubens, \& Verdonck, 1972). Furthermore, one study found that testosterone of Octopus maya males increased as they became mature but decreased as they aged (Avila-Poveda et al., 2015). Human females also show a decrease in testosterone; however, as they grow older, testosterone increases again (Azziz \& Koulianos, 1991). Similarly, Octopus maya females saw a slight decrease in testosterone, after sexual maturation (Avila-Poveda et al., 2015). 
Although hormone concentrations were different throughout life stages, it seems that directly after the acute stressor, dermal estrogen, progesterone, and testosterone in females remained the same. This finding suggests that the reproductive hormones are not influenced by an acute stressor in females (both reproductive and senescent). Chronic stressors suppress reproduction, but acute stressors must be particularly severe to do so (Cameron, 2004). Poorly timed acute stressors could disrupt critical reproductive events, causing a suppression in reproduction (Moberg \& Mench, 2000), and a decrease in estradiol and testosterone concentrations (Fischer \& Romero, 2018). However, whether acute stressors have a negative effect on reproduction reported inconsistently in several studies. (Moberg \& Mench, 2000; Moore \& Jessop, 2003). Although, it seems as through acute stressors did not affect dermal reproductive hormones in the short term in 0 . bimaculoides, it does demonstrate that the swabs were able to produce repeatable results within individuals.

Reproductive males did show a significant increase in dermal testosterone at 105 minutes post-stressor. This could be an indication of rapid changes in hormones associated with aggression. Higher levels of testosterone are known to cause aggression in vertebrates (Davies et al., 2015; Marler \& Moore, 1989). Aggression in octopuses has been observed in mating displays (Huffard et al., 2010) and antagonistic signals (Scheel, Godfrey-Smith, \& Lawrence, 2016). If testosterone in these octopus also serves as a behavioral mediator of circumstances and not just in a role of sperm production and mating, then the rapid change in testosterone may be part of a larger stress response syndrome.

Previous research has been concerned with testosterone and cortisol cross-reacting to the EIA antibodies (Touma \& Palme, 2005). However, here, the dermal testosterone peaked at 90 mins results which do not follow the same exact pattern as the cortisol that peaked at 15 minutes. Biologically, testosterone and cortisol may respond similarly to stress by preparing an animal for aggressive social interactions. For example, high ranking male baboons (Papio anubis) also had an increase in testosterone along with glucocorticoids (Sapolsky \& Sapolsky, 1986). Aggression is known in cephalopods (Cummins et al., 2011; Huffard \& Bartick, 2015; Huffard, Caldwell, \& Boneka, 2010); however, testosterone has never been measured in relation to this aggression.

In conclusion, we measured cortisol and reproductive hormones with non-invasive dermal swabs for the first time with 0 . bimaculoides and validated the mucus swab technique to measure concentrations of sex hormones: testosterone, progesterone, and estradiol. We also demonstrated the influence of age class on reproductive and stress hormones. By studying changes in hormones throughout reproductive and senescent life stages, we now have a more complete picture detailing longitudinal changes of cephalopod reproduction. One of the most promising finds from this study is the repeatability of this technique. Long-term studies using swabbing techniques on individuals - from juvenile to senescent could permit measures of changes in reproductive hormones throughout life, along with more studies into the shortchanges of testosterone in reproductive males. This technique could also be used to investigate factors eliciting shortchanges in testosterone of reproductive males. Future studies should investigate the relationship between testosterone production and the presence of spermatozoa. Longitudinal studies 
describing hormone shifts for more cephalopod species will help broaden our general understanding of cephalopod physiology.

This dermal swab technique has many applications for management, research, and understanding more about cephalopod behavior and physiology. As culturing (Vidal et al., 2014) and octopus farming (VazPires, Seixas, \& Barbosa, 2004) become more common, understanding changes in reproduction will become imperative to more successful breeding practices. In the future, collecting dermal mucous swabs throughout the entirety of an individual cephalopod's life span will provide a baseline for patterns in a healthy, well-kept octopus. Deviation from these patterns may indicate welfare issues or poor care. Poor health from environmental issues can sometimes manifest with symptoms similar to senescence, making it difficult for researchers or aquarists to diagnose health issues (Gestal et al., 2019). Whether to euthanize or allow senescent octopuses to live out their life remains an open question in animal welfare (Sykes, et al., Andrade, 2012).

\section{Declarations}

Acknowledgements:

We thank Dan Calzarette for help caring for the animals used in this study. We thank Katie Fowler from Lincoln Park Zoo's Endocrinology Laboratory for technical assistance. We also thank the Brown lab at UIC for valuable discussion and feedback. The Davee Foundation provided funding for this research. We would like to thank the Marine Biological Laboratory's Cephalopod Program for the use of animals and facilities.

Funding: Funding was provided by the Davee Foundation.

Conflicts of Interest/ Competing interests: Authors have no conflicts of intest

Availability of data and material:

Code Availability: Not Applicable

Authors' Contributions:

Stephanie Chancellor: Conceptualization, Methodology, Investigation, Formal analysis, Writing- Original Draft, Visualization, Project administration

Bret Grasse: Resources, Support, Supervision

Taylor Sakmar: Resources, Support

Joel S. Brown: Conceptualization, Methodology, Supervision, Writing- Review and Editing

David Scheel: Conceptualization, Writing- Review and Editing 
Rachel M. Santymire: Methodology, Formal Analysis, Resources, Validation, Writing- Original Draft, Visualization, Supervision, Funding acquisition

Ethics approval: Due to the use of invertebrates in the United States, approval was not necessary.

\section{References}

1. Albertin, C. B., \& Simakov, O. (2020). Cephalopod Biology: At the Intersection Between Genomic and Organismal Novelties. Annual Review of Animal Biosciences, 8(1), 71-90.

https://doi.org/10.1146/annurev-animal-021419-083609

2. Albertin, C. B., Simakov, O., Mitros, T., Wang, Z. Y., Pungor, J. R., Edsinger-Gonzales, E., ... Rokhsar, D. S. (2015). The octopus genome and the evolution of cephalopod neural and morphological novelties. Nature, 524(7564), 220-224. https://doi.org/10.1038/nature14668

3. Amaral, R. S., Rosas, F. C. W., Da Silva, V. M. F., Nichi, M., \& Oliveira, C. A. (2013). Endocrine monitoring of the ovarian cycle in captive female Amazonian manatees (Trichechus inunguis). Animal Reproduction Science, 142(1-2), 84-88. https://doi.org/10.1016/j.anireprosci.2013.09.001

4. Anderson, R. C., Wood, J. B., Byrne, R. A., \& Octopus, R. A. B. (2002). Octopus Senescence: The Beginning of the End Octopus Senescence: The Beginning of the End. Journal of Applied Animal Welfare Science, 5(4), 275-283. https://doi.org/10.1207/S15327604JAWS0504

5. Avila-Poveda, O. H., Montes-Pérez, R. C., Benitez-Villalobos, F., \& Rosas, C. (2013). Development and Validation of a Solid-Phase Radioimmunoassay for Measuring Progesterone and Testosterone in Octopus Gonad Extracts. Malacologia, 56(1 \& 2), 121-134. https://doi.org/10.4002/040.056.0209

6. Azevedo, A., Bailey, L., Bandeira, V., Dehnhard, M., Fonseca, C., de Sousa, L., \& Jewgenow, K. (2019). Correction: Age, sex and storage time influence hair cortisol levels in a wild mammal population (PLoS ONE (2019) 14: 8 (e0221124) DOi: 10.1371/journal.pone.0221124). PLoS ONE, 14(9), 1-17. https://doi.org/10.1371/journal.pone.0222963

7. Azziz, R., \& Koulianos, G. (1991). Adrenal androgens and reproductive aging in females. Seminars in Reproductive Endocrinology, 9(3), 249-260. https://doi.org/10.1055/s-2007-1019416

8. Boyle, P.R. (1983). Cephalopod Life Cycles, Vol. 1: Species Accounts. London: Academic Press

9. Chancellor, S., Abbo, L., Grasse, B. Sakmar, T., Brown, J.S., Scheel, D., Santymire, R.M. Validation for measuring glucocortcoids in mucous secretions of laboratory cephalopods. In Submission.

10. Cameron, J. L. (2004). Interrelationships between Hormones, Behavior, and Affect during adolescence. Annals of the New York Academy of Sciences, 1021(1), 110-123.

11. D’Aniello, A., Di Cosmo, A., Di Cristo, C., Assisi, L., Botte, V., \& Di Fioe, M. M. (1996). Occurence of Sex Steroid Hormones and Their Binding Protiens in Octopus vulgaris Lam. Biocheimcal and Biophysical Research Communcations, 227, 782-788. https://doi.org/10.1039/c2dt32206d

12. Davies, S., Gao, S., Valle, S., Bittner, S., Hutton, P., Meddle, S. L., \& Deviche, P. (2015). Negative energy balance in a male songbird, the Abert's towhee, constrains the testicular endocrine response to 
luteinizing hormone stimulation. Journal of Experimental Biology, 218(17), 2685-2693. https://doi.org/10.1242/jeb.123042

13. Degen, A. A., Weil, S., Rosenstrauch, A., Kam, M., \& Dawson, A. (1994). Seasonal plasma levels of luteinizing and steroid hormones in male and female domestic ostriches (Struthio camelus). General and Comparative Endocrinology. https://doi.org/10.1006/gcen.1994.1003

14. De Mercado, E., Larrán, A. M., Pinedo, J., \& Tomás-Almenar, C. (2018). Skin mucous: A new approach to assess stress in rainbow trout. Aquaculture, 484(October 2017), 90-97.

https://doi.org/10.1016/j.aquaculture.2017.10.031

15. Devenport L, Knehans A, Sundstrom A, Thomas T 1989 Corticosterone's dual metabolic actions. Life Sci 45:1389-1396

16. Dloniak, S. M., French, J. A., Place, N. J., Weldele, M. L., Glickman, S. E., \& Holekamp, K. E. (2004). Non-invasive monitoring of fecal androgens in spotted hyenas (Crocuta crocuta). General and Comparative Endocrinology, 135(1), 51-61. https://doi.org/10.1016/j.ygcen.2003.08.011

17. Di Cosmo, A., Di Cristo, C., \& Paolucci, M. (2001). Sex steroid hormone fluctuations and morphological changes of the reproductive system of the female of Octopus vulgaris throughout the annual cycle. J Exp. Zool, 289(1), 33-47. https://doi.org/10.1002/1097-010X(20010101/31)289

18. Doubleday, Z. A., Prowse, T. A. A., Arkhipkin, A., Pierce, G. J., Semmens, J., Steer, M., ... Gillanders, B. M. (2016). Global proliferation of cephalopods. Current Biology, 26(10), R406-R407. https://doi.org/10.1016/j.cub.2016.04.002

19. Fischer, C. P., \& Romero, L. M. (2018). Chronic captivity stress in wild animals is highly speciesspecific. Conservation Physiology, 7, 1-38. https://doi.org/10.1093/conphys/coz093

20. Gestal, C., Pascual, S., Guerra, Á., Fiorito, G., \& Vieites, J. M. (2019). Handbook of Pathogens and Diseases in Cephalopods. Springer Open. https://doi.org/10.1007/978-3-030-11330-8

21. Graham, L., Schwarzenberger, F., Möstl, E., Galama, W., \& Savage, A. (2001). A versatile enzyme immunoassay for the determination of progestogens in feces and serum. Zoo Biology, 20(3), 227236. https://doi.org/10.1002/zoo.1022

22. Hanlon, R. T., \& Messenger, J. B. (2018). Cephalopod Behaviour (Second). Cambridge.

23. Huffard, C. L., Caldwell, R. L., Boneka, F., Indonesia, C. I., Science, M., \& Ratulangi, U. S. (2010). Malemale and male-female aggression may 3 influence mating associations in wild octopuses (Abdopus aculeatus). Journal of Comparative Psychology, 124(1), 38-46.

24. Kaufman, J. M., T'sjoen, G., \& Vermeulen, A. (2012). Androgens in male senescence. Testosterone: Action, Deficiency, Substitution, Fourth Edition, 336-371. https://doi.org/10.1017/СB09781139003353.017

25. Keay, J., Bridgham, J. T., \& Thornton, J. W. (2006). The Octopus vulgaris estrogen receptor is a constitutive transcriptional activator: Evolutionary and functional implications. Endocrinology, 147(8), 3861-3869. https://doi.org/10.1210/en.2006-0363

26. Lafont, R., \& Mathieu, M. (2007). Steroids in aquatic invertebrates. Ecotoxicology, 16(1), 109-130. https://doi.org/10.1007/s10646-006-0113-1

Page 13/21 
27. Larson, S. E., \& Anderson, R. C. (2010). Fecal hormones measured within giant pacific octopuses Enteroctopus dofleini. Journal of Aquatic Animal Health, 22(3), 152-157. https://doi.org/10.1577/H09-027.1

28. Loeding, E., Thomas, J., Bernier, D., \& Santymire, R. (2011). Using fecal hormonal and behavioral analyses to evaluate the introduction of two sable antelope at Lincoln Park Zoo. Journal of Applied Animal Welfare Science: JAAWS, 14(3), 220-246. https://doi.org/10.1080/10888705.2011.576968

29. Malham, S. K., Lacoste, A., Gélébart, F., Cueff, A., \& Poulet, S. A. (2002). A first insight into stressinduced neuroendocrine and immune changes in the octopus Eledone cirrhosa. Aquatic Living Resources, 15(3), 187-192. https://doi.org/10.1016/S0990-7440(02)01173-7

30. Marler, C. A., \& Moore, M. C. (1989). Time and energy costs of aggression in testosterone-implanted free living male mountain spiny lizards Sceloporus-jarrovi. Physiological Zoology, 62(May), 13341350.

31. Mason, G. J. (2010). Species differences in responses to captivity: Stress, welfare and the comparative method. Trends in Ecology and Evolution, 25(12), 713-721.

https://doi.org/10.1016/j.tree.2010.08.011

32. Mather, J. A. (2006). Behaviour Development: A Cephalopod Perspective. International Journal of Comparative Psychology, 19, 98-115.

33. McCauley, D. J., Pinsky, M. L., Palumbi, S. R., Estes, J. A., Joyce, F. H., \& Warner, R. R. (2015). Marine defaunation: Animal loss in the global ocean. Science, 347(6219). https://doi.org/10.1126/science.1255641

34. Moberg, G. P., \& Mench, J. A. (2000). Basic Principles and Implications for Animal Welfare Basic Principles and Implications for.

35. Monfort, S. L., Mashburn, K. L., Brewer, B. A., \& Creel, S. R. (1988). Evauluating Adrenal Activity in African Wild Dogs (Lycaon pictus) by Fecal Corticosteroid Analysis. Journal of Zoo and Wildlife Medicine, 29(2), 129-133.

36. Moore, I. T., \& Jessop, T. S. (2003). Stress, reproduction, and adrenocortical modulation in amphibians and reptiles. Hormones and Behavior, 43(1), 39-47. https://doi.org/10.1016/S0018506X(02)00038-7

37. Nicol, S., Andersen, N. A., \& Jones, S. M. (2005). Seasonal variations in reproductive hormones in free-ranging echidnas (Tachyglossus aculeatus): Interaction between reproduction and hibernation. General and Comparative Endocrinology, 144(3), 204-210. https://doi.org/10.1016/j.ygcen.2005.05.013

38. O'Dor, R. K., \& Wells, M. J. (1978). Reproduction versus somatic growth: hormonal control in Octopus vulgaris. The Journal of Experimental Biology, 77, 15-31.

39. Palme, R. (2005). Measuring fecal steroids: Guidelines for practical application. Annals of the New York Academy of Sciences, 1046, 75-80. https://doi.org/10.1196/annals.1343.007

40. Rich, E. L., \& Romero, L. M. (2005). Exposure to chronic stress downregulates corticosterone responses to acute stressors. American Journal of Physiology - Regulatory Integrative and 
Comparative Physiology, 288(6 57-6). https://doi.org/10.1152/ajpregu.00484.2004

41. Robin, J. P., Roberts, M., Zeidberg, L., Bloor, I., Rodriguez, A., Briceño, F., ... Mather, J. (2014).

Transitions during cephalopod life history: The role of habitat, environment, functional morphology and behaviour. Advances in Marine Biology (Vol. 67). https://doi.org/10.1016/B978-0-12-8002872.00004-4

42. Romero, L. M. (2004). Physiological stress in ecology: Lessons from biomedical research. Trends in Ecology and Evolution, 19(5), 249-255. https://doi.org/10.1016/j.tree.2004.03.008

43. Santymire, R. M., Manjerovic, M. B., \& Sacerdote-Velat, A. (2018). A novel method for the measurement of glucocorticoids in dermal secretions of amphibians. Conservation Physiology, 6(1), 1-12. https://doi.org/10.1093/conphys/coy008

44. Sapolsky, R. M., \& Sapolsky, R. M. (1986). Stress-induced elevation of testosterone concentrations in high ranking baboons: Role of catecholamines. Endocrinology, 118(4), 1630-1635. https://doi.org/10.1210/endo-118-4-1630

45. Scheel, D., Godfrey-Smith, P., \& Lawrence, M. (2016). Signal use by octopuses in agonistic interactions. Current Biology, 26(3), 377-382. https://doi.org/10.1016/j.cub.2015.12.033

46. Schell, C. J., Young, J. K., Lonsdorf, E. V., \& Santymire, R. M. (2013). Anthropogenic and physiologically induced stress responses in captive coyotes. Journal of Mammalogy, 94(5), 11311140. https://doi.org/10.1644/13-MAMM-A-001.1

47. Schultz, D. R., Perez, N., Tan, C. K., Mendez, A. J., Capo, T. R., Snodgrass, D., ... Serafy, J. E. (2005). Concurrent levels of 11-ketotestosterone in fish surface mucus, muscle tissue and blood. Journal of Applied Ichthyology, 21(5), 394-398. https://doi.org/10.1111/j.1439-0426.2005.00650.x

48. Sykes, A. V., Baptista, F. D., Gonçalves, R. A., \& Andrade, J. P. (2012). Directive 2010/63/EU on animal welfare: A review on the existing scientific knowledge and implications in cephalopod aquaculture research. Reviews in Aquaculture, 4(3), 142-162. https://doi.org/10.1111/j.1753-5131.2012.01070.x

49. Touma, C., \& Palme, R. (2005). Measuring fecal glucocorticoid metabolites in mammals and birds: The importance of validation. Annals of the New York Academy of Sciences, 1046(0), 54-74. https://doi.org/10.1196/annals.1343.006

50. Wells, B. Y. M. J., \& Wells, J. (1959). Hormonal Control of Sexual Maturity in Octopus. Journal of Experimental Biology, 36(1), 1-33.

51. Vermeulen, A., Rubens, R., \& Verdonck, L. (1972). Testosterone Secretion and Metabolism in Male Senescence. The Journal of Clinical Endocrinology and Metabolism, 34(4), 730-735.

52. Young, K. M., Walker, S. L., Lanthier, C., Waddell, W. T., Monfort, S. L., \& Brown, J. L. (2004). Noninvasive monitoring of adrenocortical activity in carnivores by fecal glucocorticoid analyses. General and Comparative Endocrinology, 137(2), 148-165.

https://doi.org/10.1016/j.ygcen.2004.02.016

\section{Figures}



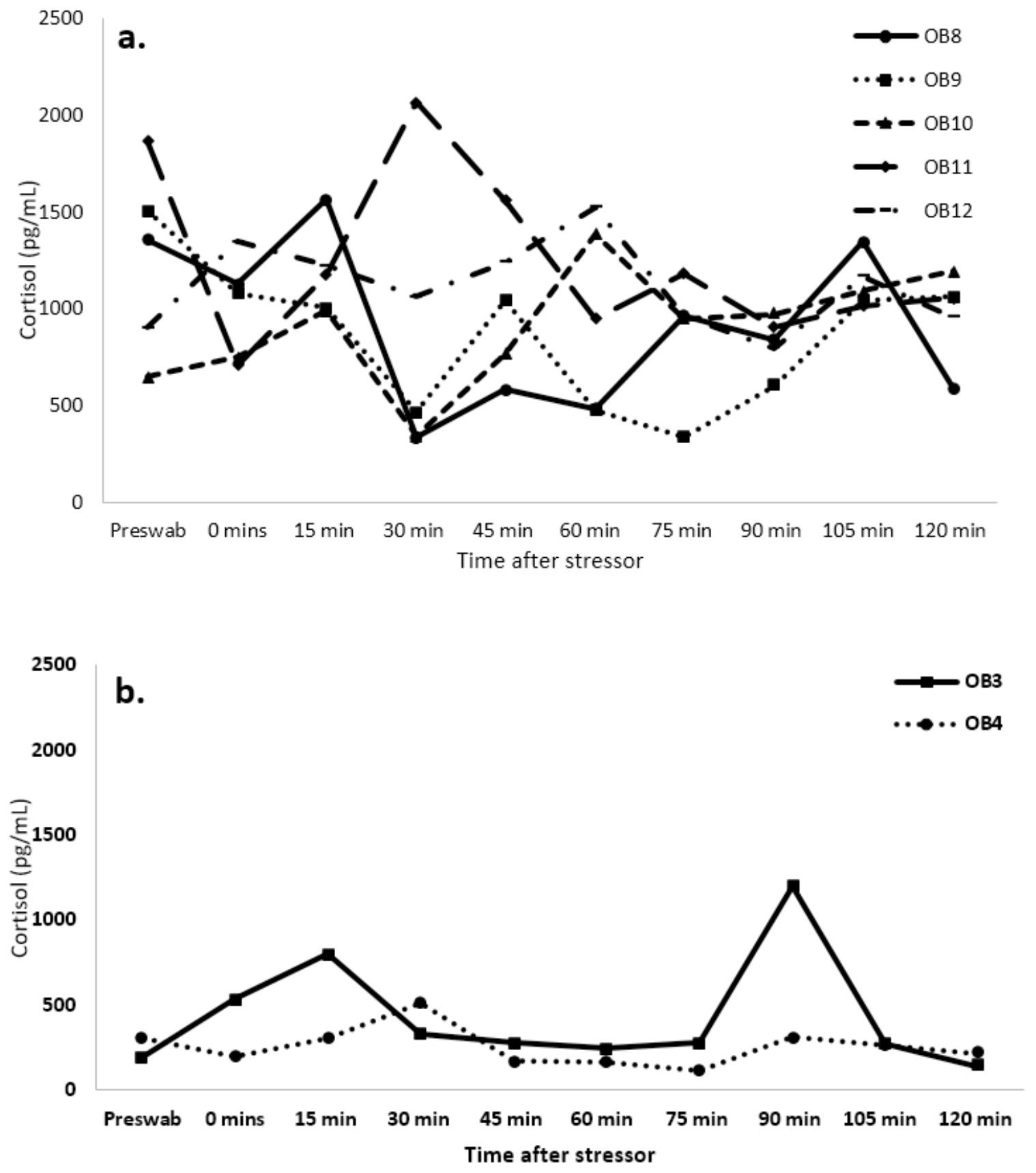

\section{Figure 1}

Dermal cortisol concentrations $(\mathrm{pg} / \mathrm{mL}$ swab) over time after stress test (chasing octopus around for 5 minutes with a net) for $A$ ) senescent females $(N=5)$; and $B$ ) reproductive female $(N=2)$ Octopus bimaculoides. 

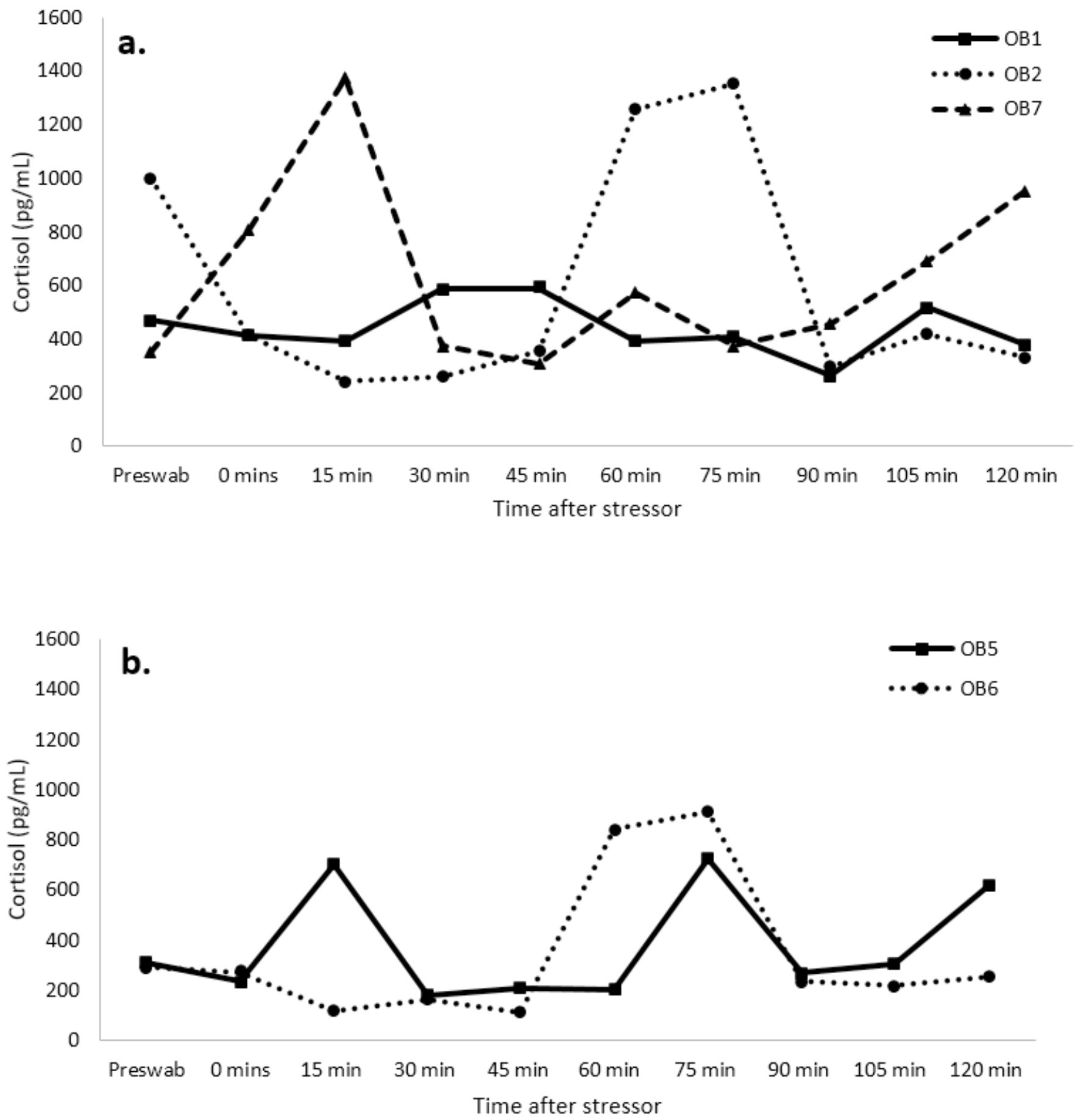

Figure 2

Dermal cortisol concentrations $(\mathrm{pg} / \mathrm{mL}$ swab) over time after stress test (chasing octopus around for 5 minutes with a net) for $A)$ senescent male $(N=4)$; and $B$ ) reproductive male $(N=2)$ Octopus bimaculoides. 


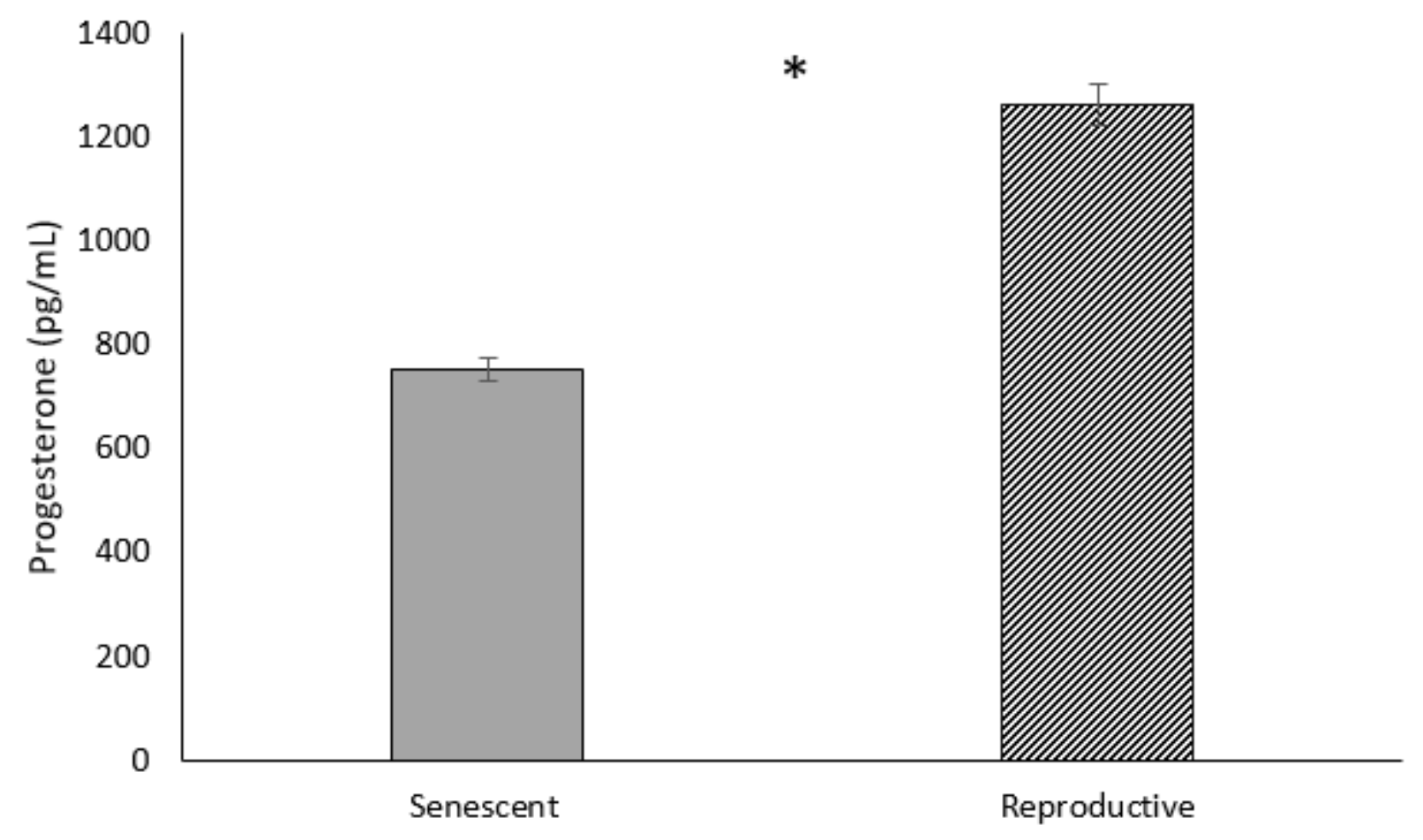

Figure 3

Mean $( \pm$ SEM) progesterone concentrations of for senescent $(n=5)$ and reproductive $(n=2)$ Octopus bimaculoides 2 hours after stress test. Asterisk denotes difference $(p<0.05)$ between age and progesterone concentrations.

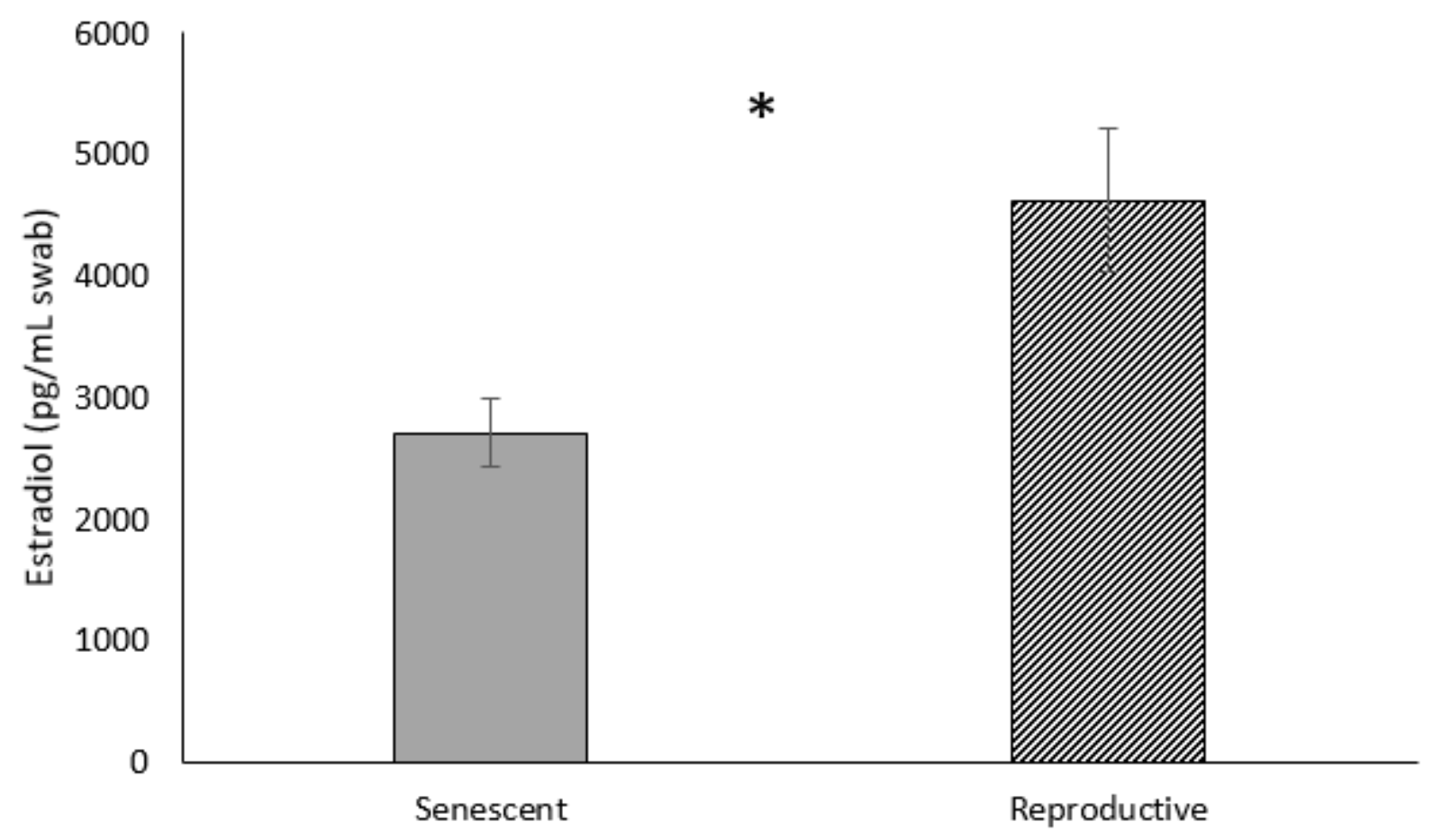


Figure 4

Mean $( \pm$ SEM) of all estradiol for senescent $(n=5)$ and reproductive $(n=2)$ Octopus bimaculoides from 2 hours after stress test. Asterisk denotes difference $(p<0.05)$ between age and estradiol concentrations.

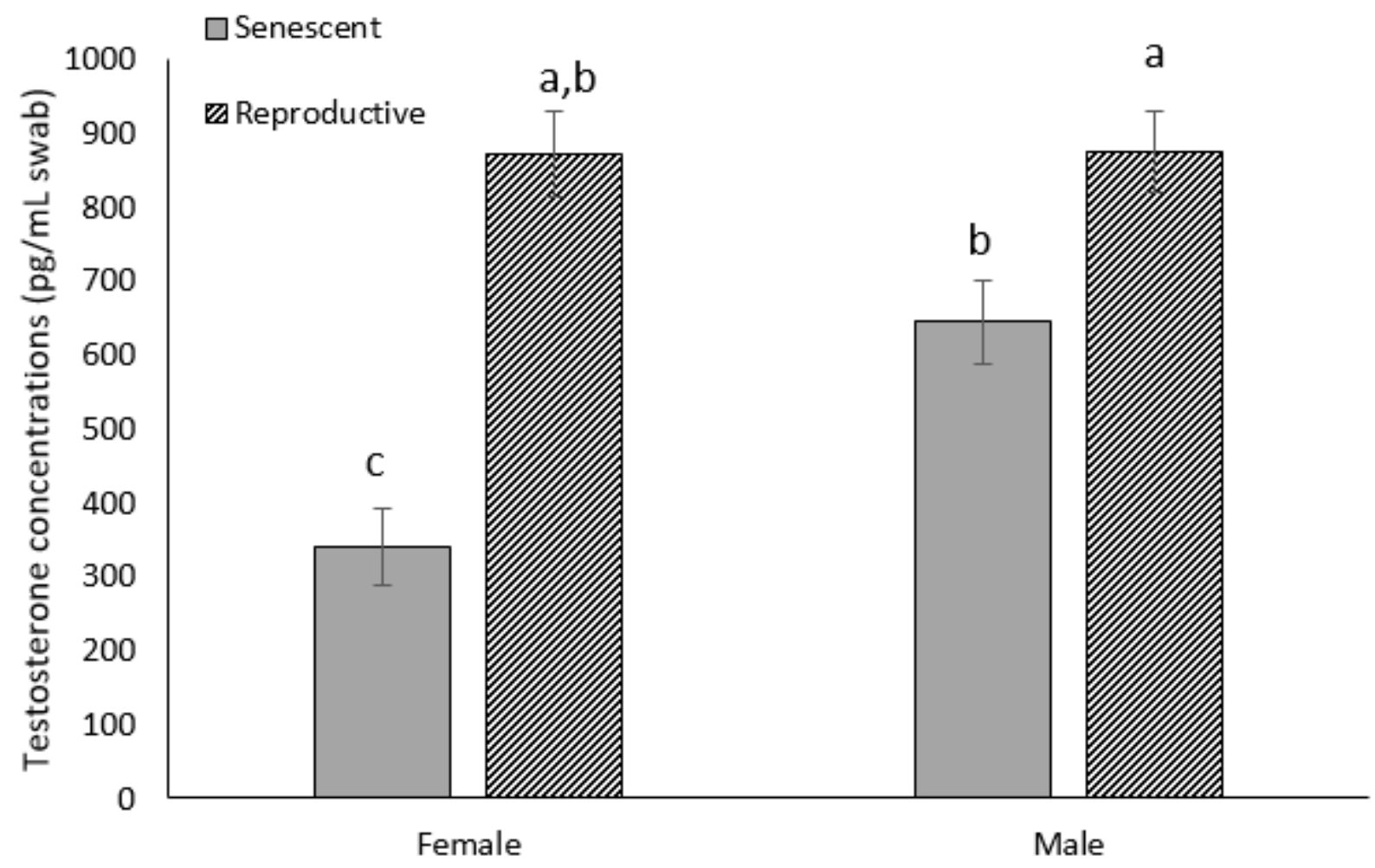

Figure 5

Mean $( \pm$ SEM) testosterone concentrations of senescent $(n=8)$ and reproductive $(n=4)$ Octopus bimaculoides 2 hours after stress test. Letters denote differences $(p<0.05)$ between sex, age, and testosterone concentration. 

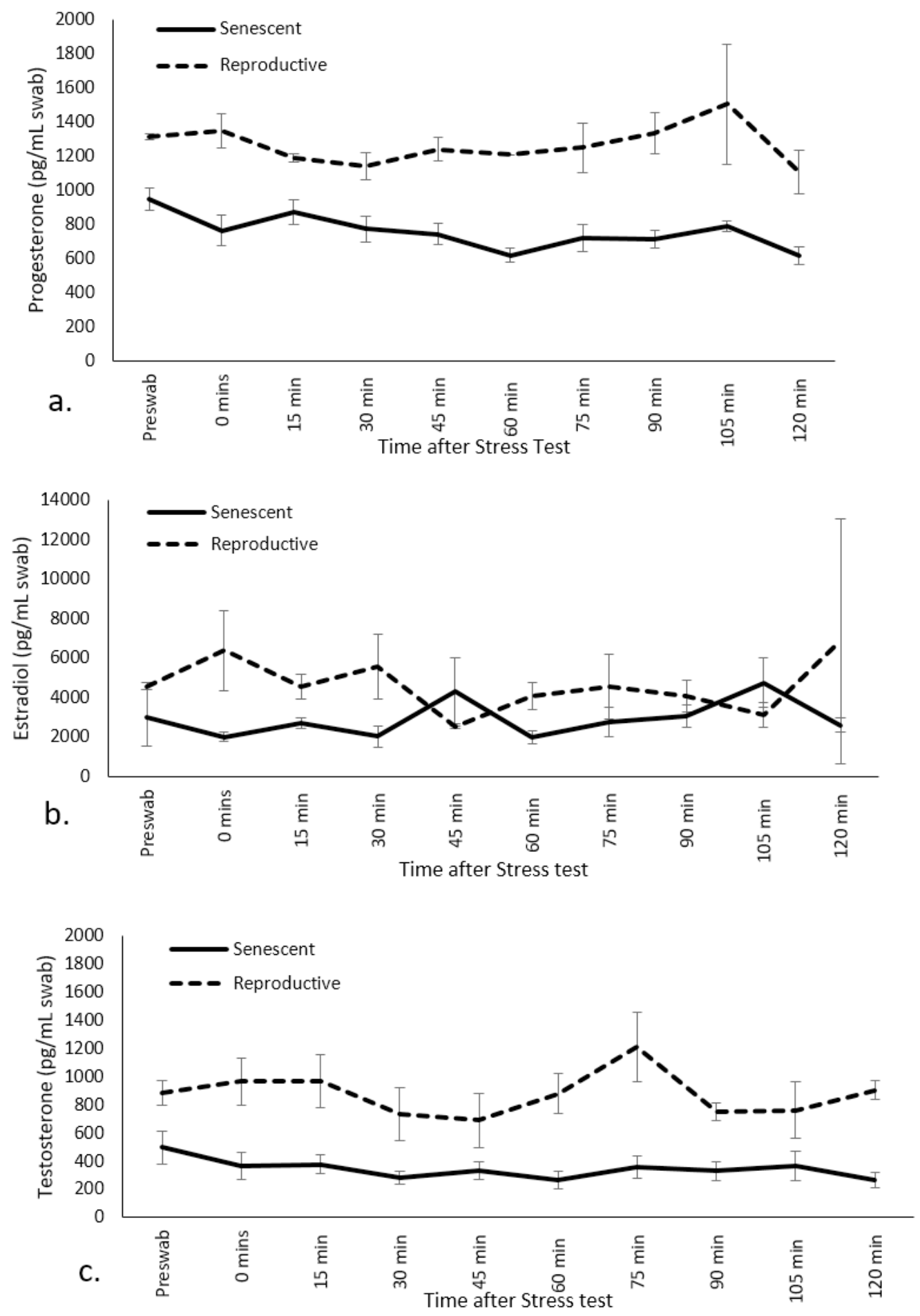

\section{Figure 6}

Mean ( \pm SEM) of progesterone $(A)$, estradiol $(B)$, and testosterone $(C)$ for senescent $(N=5)$ and reproductive $(\mathrm{N}=2)$ Octopus bimaculoides females 2 hours after stress test. 


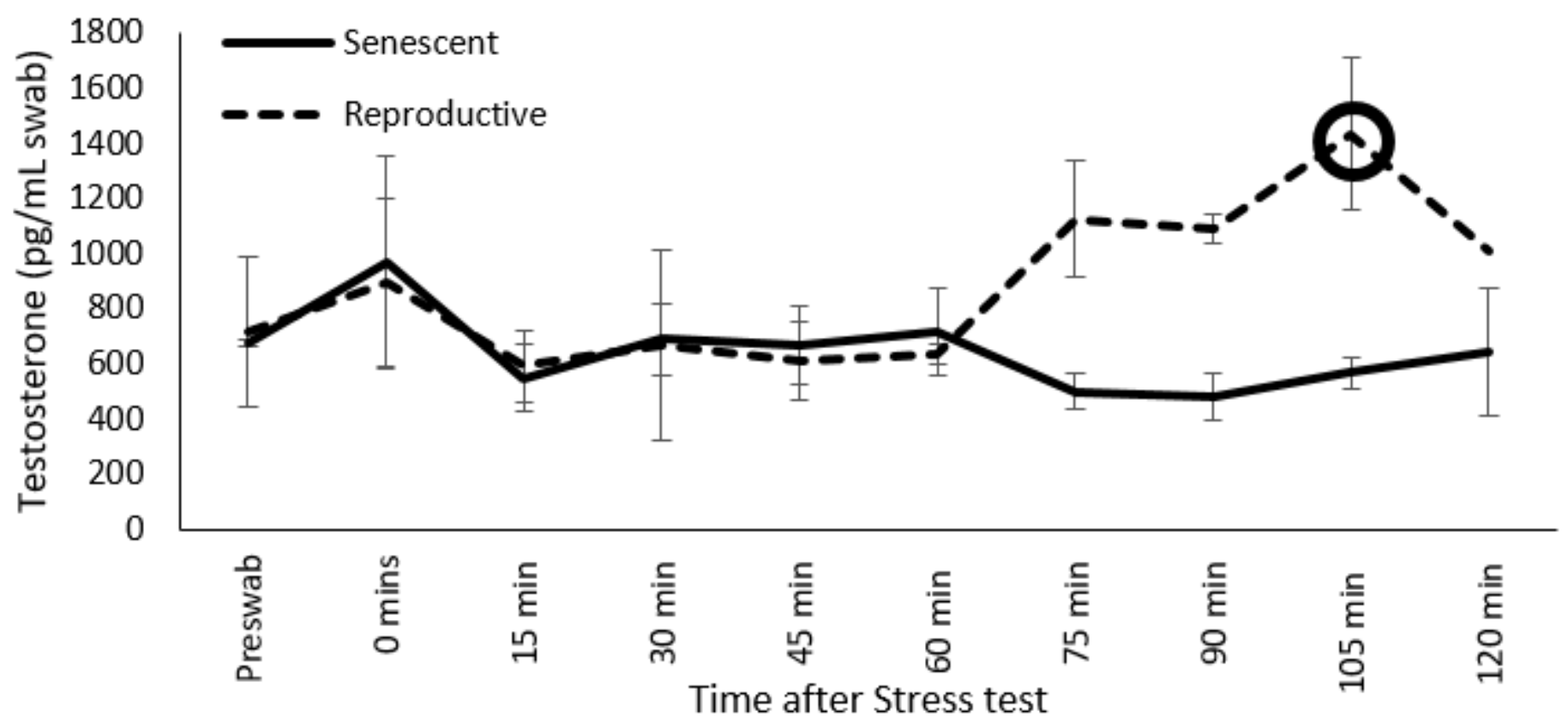

Figure 7

Mean $( \pm$ SEM) testosterone levels for senescent $(\mathrm{N}=3)$ and reproductive $(\mathrm{N}=2)$ Octopus bimaculoides males 2 hours after stress test. Circle represents a 2 -fold change in testosterone hormone. 